\title{
Failure patterns and survival in patients with nasopharyngeal carcinoma treated with intensity modulated radiation in Northwest China: A pilot study
}

Jianhua Wang ${ }^{\dagger}$, Mei Shi ${ }^{*}$, Yuesheng Hsia ${ }^{\dagger}$, Shanquan Luo, Lina Zhao, Man Xu, Feng Xiao, Xuehai Fu, Jianping Li, Bin Zhou and Xiaoli Long

\begin{abstract}
Purpose: To evaluate the clinical outcomes and patterns of failure in patients with nasopharyngeal carcinoma (NPC) treated with intensity modulated radiotherapy (IMRT) in Northwest China.

Methods and materials: From January 2006 to December 2009, 138 NPC patients were treated at Xijing Hospital. Of them, 25 cases with stage I-II received IMRT only, 113 cases with stage III-IVb received IMRT plus accomplished platinum-based chemotherapy. The IMRT prescribed dose was PTV 68-74 Gy to gross disease in nasopharynx and 66-72 Gy to positive lymph nodes in 30-33 fractions, and high risk and low risk region PTV was 60-63 Gy and 50.4 56 Gy in 30 33 and 28 fractions respectively. Plasma Epstein Barr virus (EBV) DNA load was measured before treatment. The clinical toxicities, outcomes and patterns of failure were observed.
\end{abstract}

Results: The median follow up time was 23 months (range 2 to 53 months). EBV infection positive was only 15.9\%. Overall disease failure developed in 36 patients, 99\% belonged to stage III/IV disease. Among these, there were 26 distant metastases, 6 local recurrence, and 4 regional recurrence. The 3-year local control rate(LCR), distant metastasis-free survival (MFS), disease-free survival (DFS) and the overall survival (OS) was 93.9\%, 79.5\%, 70\% and 83.1\% respectively. Multivariate analyses revealed that age and anemia pre-radiotherapy were independent predictors for OS.

Conclusion: IMRT with or without chemotherapy can improve the long term survival of NPC patients in Northwest China. Distant metastasis becomes the main cause of treatment failure. Age and anemia before radiotherapy were the main prognosis factors of NPC patients.

Keywords: nasopharyngeal carcinoma, intensity modulated radiotherapy, chemotherapy, pattern of failure, survival

\section{Introduction}

Nasopharyngeal carcinoma (NPC) presents a remarkably distinctive ethnic and geographic distribution, it is a rare malignancy in northwestern China but is more common in Southern China or Southeast Asia. The Epstein Barr virus (EBV) infection is frequently associated with the patients in Southern China [1,2]. NPC is highly sensitive to radiation, early stage NPC is often curable by

\footnotetext{
* Correspondence: meishifmmu@126.com

+ Contributed equally

Department of Radiation Oncology, Xijing Hospital, Fourth Military Medical University, No.15 Changle West Road, Xi'an, China
}

radiation, and radiotherapy is the mainstay treatment strategy. However approximately $70 \%$ of newly diagnosed NPC patients present with stage III or IV disease, which are prone to suffer from locoregional recurrence or distant metastases after radiotherapy alone [3-5]. Hence, treatment of advanced NPC usually requires combined chemoradiation therapy. Forepart randomized trials displayed adjuvant chemotherapy delivered with conventional radiotherapy failed to improve NPC overall survival [6], those results were subsequently confirmed by a number of studies [7]. Although the neoadjuvant chemotherapy has demonstrated improved locoregional

\section{C) Biomed Central}


control and event-free survival, its benefit on overall survival has not yet to be confirmed [8]. In a word, it lacks powerful evidences to demonstrate overall survival benefits from chemotherapy [9], even through randomized trials of concurrent chemoradiation therapy for advanced NPC have showed a progression-free survival [5,10-12].

In pattern of conventional 2 dimensional radiotherapy, many factors are associated with the NPC prognosis, including age, gender, anemia, TNM stage, histopathology, radiation dose, radiation field, and combined manner of chemotherapy $[1,13,14]$. Nasopharynx is surrounded by more radiosensitive structures, simultaneity nasopharyngeal carcinoma cell is easy to infiltrate and spread towards surrounding normal organs. Those result in NPC irradiation target volumes are very irregular, conventional radiotherapy adopted lateral opposing fields for NPC rarely achieves the prerequisite dose and precision to tumor targets. On account of advancement of radicalized technology, especially IMRT has been applied, the limitation of conventional 2D radiotherapy for NPC can be overcome by IMRT, synchronously, traditional prognostic factors seem to change stealthily. IMRT can contribute to a high dose to the tumor while keeping down normal tissue complications by limiting radiation dose to normal tissues, the different organs can receive different fractional dose at the same fraction of treatment, results in the best radicalized biological effectiveness $[15,16]$. Several series reported showed excellent local control of more than $90 \%$ in NPC received with IMRT $[16,17]$, even among patients with advanced T3-4 diseases [18]. Especially the phase II 0225 Trial confirmed the excellent outcomes, IMRT with or without chemotherapy in the treatment of NPC achieved the almost indistinctive benefit in local progression-free and overall survivals [19].

Even though numerous favourable reports for NPC have focus on IMRT, IMRT can unfold a novel threshold for NPC, the result still need to be confirmed in different region. The present retrospective study exhibited clinical outcomes and patterns of failure in NPC patients treated with IMRT in Northwest China.

\section{Materials and methods}

All patients were native and resided in northwest China, consisted of 138 consecutive untreated patients who had histologically confirmed NPC before radiotherapy between January 2006 and December 2009. Stage I-IVb NPC histologically classified by the World Health Organisation (WHO) system [20]: Stage I, representing squamous cell carcinoma, is similar to carcinomas arising from other sites of head and neck. Stage II is characterised as non-keratinizing carcinoma. Stage III, representing undifferentiated carcinoma. TNM classification system by AJCC [21,22]. Patients who had evidence of distant metastasis were remove from this treatment choice. Of those patients. 25 cases with stage I-II received IMRT only, 113 cases with stage III-IVb received IMRT plus accomplished platinum-based chemotherapy. Patient characteristics and treatment factors are shown in Table 1.

Pretreatment evaluations consisted of complete physical examination, nasopharyngoscopy, Magnetic resonance imaging (MRI) or computed tomography (CT) imaging of the nasopharyngeal region and neck. Positron emission tomography (PET) was optional. The routine examine included chest X-ray, complete blood

Table 1 Patient and disease characteristics

\begin{tabular}{|c|c|c|}
\hline \multirow[b]{2}{*}{ Characteristics } & \multicolumn{2}{|c|}{ Patients } \\
\hline & No. & $\%$ \\
\hline \multicolumn{3}{|l|}{ Age, years } \\
\hline Median & 46 & \\
\hline Range & $11-72$ & \\
\hline \multicolumn{3}{|l|}{ Sex } \\
\hline Male & 104 & 75.4 \\
\hline Female & 34 & 24.6 \\
\hline \multicolumn{3}{|l|}{ EBV infection } \\
\hline$<1000$ copy & 116 & 84.1 \\
\hline$\geq 1000$ copy & 22 & 15.9 \\
\hline \multicolumn{3}{|l|}{ Tumor factors } \\
\hline \multicolumn{3}{|l|}{ WHO histology } \\
\hline 1 & 2 & 1.5 \\
\hline$\|$ & 99 & 71.7 \\
\hline III & 37 & 26.8 \\
\hline \multicolumn{3}{|l|}{ AJCC T category } \\
\hline $\mathrm{T} 1-2$ & 100 & 72.5 \\
\hline $\mathrm{T} 3-4$ & 38 & 27.5 \\
\hline \multicolumn{3}{|l|}{ AJCC $N$ category } \\
\hline No-1 & 78 & 56.5 \\
\hline N2-3 & 60 & 43.5 \\
\hline \multicolumn{3}{|l|}{ AJCC stage } \\
\hline I & 6 & 4.4 \\
\hline$\|$ & 19 & 13.8 \\
\hline III & 64 & 46.4 \\
\hline IVa & 39 & 28.3 \\
\hline $\mathrm{IVb}$ & 10 & 7.3 \\
\hline \multicolumn{3}{|l|}{ Treatment factors } \\
\hline IMRT alone & 25 & 18.1 \\
\hline IMRT + chemotherapy & 113 & 81.9 \\
\hline \multicolumn{3}{|l|}{ Chemotherapy manner } \\
\hline Neoadjuvant chemotherapy & 43 & 31.2 \\
\hline Concurrent chemotherapy & 18 & 13.0 \\
\hline Concurrent +Adjuvant & 52 & 37.7 \\
\hline
\end{tabular}

WHO $=$ World Health Organization .

AJCC = American joint committee on carcinoma

Concurrent + Adjuvant $=$ Concurrent + Adjuvant chemotherapy 
count, serology of Epstein-Barr virus (EBV), renal and liver function tests. Anaemia assumed the HBC value: < $120 \mathrm{~g} / \mathrm{L}$ in males, $<110 \mathrm{~g} / \mathrm{L}$ in females. Additional investigations were performed for those with suspicious findings or abnormal biochemical profile.

\section{Methods}

IMRT

All patients were immobilized in the supine position with thermoplastic masks. Contrast-enhanced planning computed tomography (CT) scans with a $3 \mathrm{~mm}$ slide thickness were then obtained, with coverage from the skull vertex to $2 \mathrm{~cm}$ below the clavicles. MRI/CT images was performed for all patients for accurate delineation of tumor volumes and critical structures. The primary tumor and upper neck above the bottom of hyoid bone was treated with IMRT techniques using seven coplanar beams, inverse treatment planning was performed using the Eclipse treatment-planning system with simulated annealing. IMRT was delivered by using a simultaneousintegrated boost (SIB) technique [23].

The gross tumor volume (GTV) includes the primary nasopharyneal tumor (GTVnx) and involved lymph nodes (GTVnd) as demonstrated by imaging and physical examinations. The high-risk clinical tumor volume (CTV-1) included GTV plus $5 \mathrm{~mm}$ margin and encompassed the entire nasopharyngeal mucosa plus $5 \mathrm{~mm}$ submucosal volume. The CTV2 covers the CTV1 and area at risk, including posterior third of nasal cavity and maxillary sinus, pterygopalatine fossa, posterior ethmoid sinus, parapharyngeal space, skull base, clivus or based on tumor invasion. The CTV3 covers lower risk lymphatic levels. The planning target volume (PTV) was created based on each CTVs with an additional 3-5 mm margin, accounting for organ motion/daily treatment set-up uncertainties. In areas where the GTV or the CTV was adjacent to critical normal structures (ie, brainstem), a smaller margin was delineated.

The prescribed dose was 68-74 Gy to gross disease PTV in nasopharynx and 66-72 Gy to positive lymph nodes in 30-33 fractions, and the prescribed dose to high risk vs. low risk region PTV was 60-63 Gy vs. $50.4 \sim 56$ Gy in 30 33 and 28 fractions respectively. Treatment will be delivered once daily, 5 fractions per week. The dose received by each OAR should be no more than its tolerance limits. For patients given induction chemotherapy, the target delineations were based on the pre-chemotherapy extent as shown on the CT/ MRI images.

\section{Chemotherapy}

Except 25 patients in stage I-II, other 113 patients in stage III-IVb had additional accomplished platinumbased chemotherapy (Table 1). Various sequences and regimens of cytotoxic drugs (all cisplatin based) had been used. Neoadjuvant chemotherapy was given to 43 patients, who were in stage III IVb, mainly consisted of 2 3 cycles of PF (cisplatin $30 \mathrm{mg} / \mathrm{m} 2 / \mathrm{d}$ IV for 3 days, 5FU $800 \sim 1000 \mathrm{mg} / \mathrm{m} 2$ IV in d1-d5) or TP regimen (Docetaxel $75 \mathrm{mg} / \mathrm{m} 2$ IV in $\mathrm{d} 1$, cisplatin $30 \mathrm{mg} / \mathrm{m} 2 / \mathrm{d}$ IV for 3 days) at a 2 week interval prior to the initiation of RT treatment. Concurrent chemotherapy only was given to 18 patient mainly with cisplatin $80-100 \mathrm{mg} / \mathrm{m} 2$ on day 1-3 at 3 weekly intervals during the course of RT. Concurrent and adjuvant chemotherapy were given to 52 patients according to NPC-9901 Trial. Patients who received neoadjuvant chemotherapy were not offered adjuvant chemotherapy.

\section{Follow-up}

All patients were evaluated weekly during treatment period, after the completion of their treatment, followed-up every 3 months in the first 2 years, every 6 months between 2-5 years. Each follow-up included a complete examination, basic serum detection, chest Xray, and ultrasound of liver and abdomen. Endoscopy was performed at every visit after treatment. MRI of the head and neck areas was performed every 6 months. PET was optional in high risk incident. Toxicities were observed and scored according to the Toxicity criteria of the Radiation Therapy Oncology Group (RTOG) radiation morbidity scoring criteria at each follow-up [24].

The primary endpoints were treatment compliance and acute toxicities. The secondary endpoints of this study were late toxicities, local recurrence-free survival (LRF), regional recurrence-free survival (RRF), distant metastasis-free survival (DMF), disease-free survival (DFS) and overall survival (OS). Follow-up time was ensured from the date of treatment initiation to the date of the last contact or death. Time to failure was calculated from the date of treatment initiation to the date of the relevant event. Survival analyses were computed using the Kaplan-Meier method, $\mathrm{P}<0.05$ was considered significant. The analyses were performed with the SPSS software package (Version 13.0, SPSS Inc., Chicago, IL).

\section{Results}

\section{Patterns of failure}

The total numbers of death were 17 cases, including tumor recurrence (3 patients), distant metastasis (9 patients), both recurrence and metastasis (5 patients).

Table 2 lists the patterns of failure. The overall failure rate was $26.1 \%$ (36 patients): among these, 6 local recurrence, 4 regional recurrence, noticeable event was only 2 cases local/regional recurrence were marginal of field radiation (Figure 1), 8 patients had inside-field 
Table 2 Causes of failure

\begin{tabular}{lll}
\hline $\begin{array}{l}\text { No. of patients } \\
\text { Site }\end{array}$ & $\mathbf{n}$ & $\%$ \\
\hline Relapse & 10 & \\
$\quad$ local relapse & 6 & 4.3 \\
$\quad$ Regional relapse & 4 & 2.9 \\
Metastasis & 26 & \\
Bone & 12 & 8.9 \\
Liver & 2 & 1.5 \\
Lung & 6 & 4.4 \\
Other location & 2 & 1.5 \\
Multiple location & 4 & 2.9 \\
\hline
\end{tabular}

recurrence. The median recurrent time was 16 months (range, 4-23 months). There were 26 distant metastases $(18.8 \%)$, the most common metastasis site is bone. The median distant metastasis time was 9.5 months (range, 3-23 months). Obviously, distant metastasis was the major patterns of failure.

\section{Toxicities}

The IMRT plans showed decreased doses to normal structures and increased doses to target volumes, which might decreased the unwanted side effects. The acute toxicities were listed in Table 3. The primary toxicities were xerostomia, stomatitis, dermatitis and neutropenia, which were generally mild or moderate. The total incidence of grade 3 acute toxicities in patients received IMRT plus chemotherapy was 22 patients (19.5\%), significantly higher than those received IMRT alone 2 patients $(8,0 \%)(\mathrm{P}<0.05)$.

The late toxicities include Grade II mucositis 3 patients (2.2\%), Grade III mucositis 14 patients(10.1\%), Grade III xerostomia 16 patients (11.6\%), Grade III leucocytopenia 6 patients(4.3\%).

No grade IV acute and late toxicities were detected.

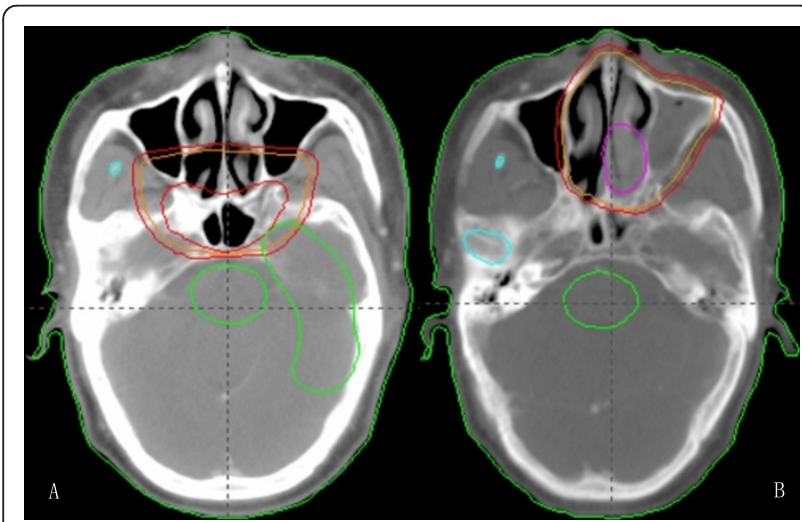

Figure 1 Intensity modulated radiotherapy plan for nasopharyngeal carcinoma. A: Before treatment; B: Failures were marginal-field after treatment.
Table 3 Acute toxicities during treatment

\begin{tabular}{clll}
\hline Acute toxicities & $\mathbf{I}(\%)$ & II (\%) & III(\%) \\
\hline Dermatitis & $29(21.0)$ & $20(14.5)$ & $7(5.1)$ \\
Stomatitis & $16(11.6)$ & $8(5.8)$ & $3(2.2)$ \\
Neutropenia & $24(17.4)$ & $13(9.4)$ & $2(1.5)$ \\
xerostomia & $28(21.1)$ & $26(18.8)$ & $12(8.7)$ \\
\hline
\end{tabular}

\section{Survival analysis}

The median follow-up time was 23 months (range, 2-53 months). 3-year OS, LRF, RFS, MFS and DFS were $83.1 \%, 93.9 \%, 96.3 \%, 79.5 \%$ and $70 \%$, respectively. Locoregional recurrences did tend to occur more frequently in the first 2 years post-treatment, resulted in the 2-year OS fall rapidly.

The value of various potential prognostic factors include age, gender, stage and use of chemotherapy on predicting local control, DMF, DFS, and OS rates were evaluated. Univariate analysis of prognostic factors in survival rates showed male, stage $\mathrm{T}$ or $\mathrm{N}$, lymph node biopsy and chemotherapy was not associated with local control, DFS, MFS and OS; Anemia before radiotherapy and age ( $\leq 50$ vs. $>50$ ) were found to be the independent predictors for OS $(\mathrm{P}=0.013$, hazard ratio [HR] 4.33, 95\% confidence interval $[\mathrm{CI}] 1.367 \sim 13.734 ; \mathrm{P}=$ 0.001 , hazard ratio [HR] 6.99, 95\% confidence interval [CI] 2.290 21.343). To adjust for the prognostic factors, the Cox regression analysis confirmed the outcomes (Figure 2, 3).

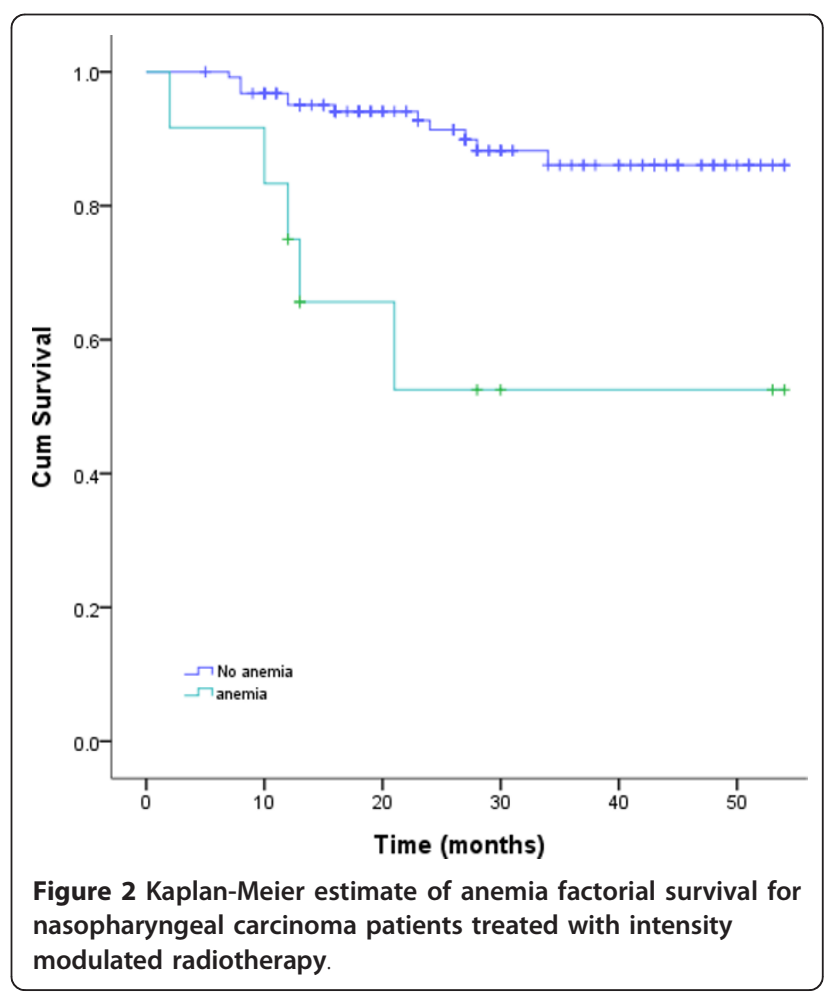




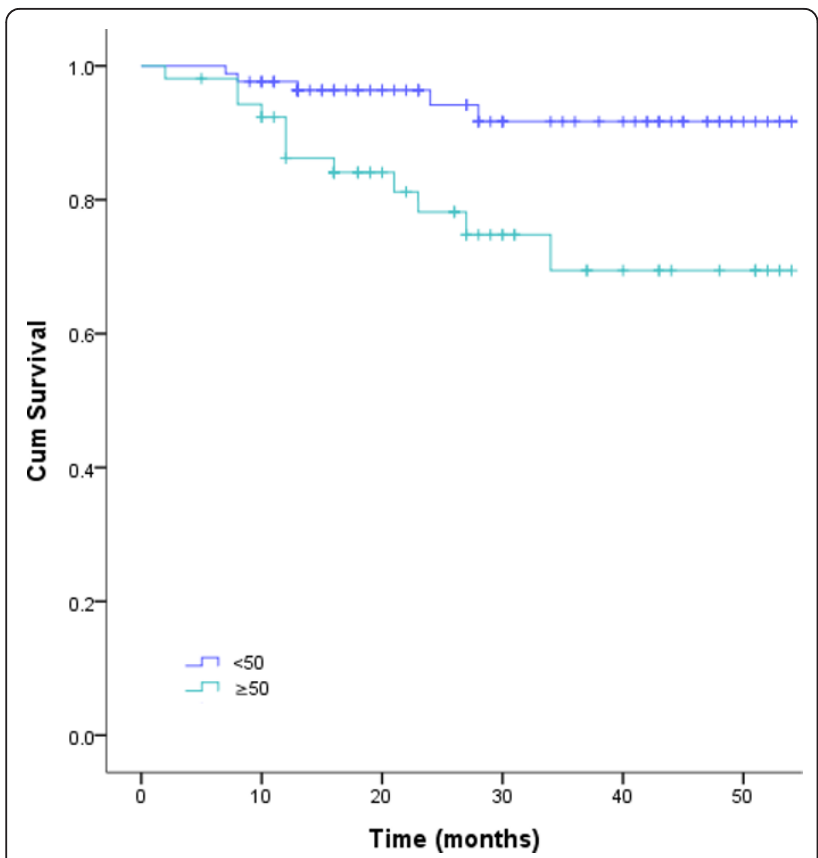

Figure 3 Kaplan-Meier estimate of age factorial survival for nasopharyngeal carcinoma patients treated with intensity modulated radiotherapy.

IMRT with or without chemotherapy provided no significant additive effect on local/regional control, 3-year MFS, DFS, and OS rates in this group of patients with advanced NPC, regardless of their T-classification or nodal status, definitively treated with IMRT in multivariate analysis $(\mathrm{P}>0.05)$. Distant metastasis becomes the main cause of treatment failure.

\section{Discussion}

NPC presents high sensitivity to radiation. Radiation alone for early NPC can achieve relatively high cure rate, however, it is disappointing for locally advanced disease. In pattern of conventional 2 dimensional radiotherapy, increasing evidences support concurrent chemoradiation to be standard treatment strategy for locally advanced NPC, its efficacy has been proven in a number of randomized phase III trails and meta-analyses $[12,13,25]$. However, it's difficult to increase OS by these arms.

IMRT has been demonstrated often to produce superior dose distributions in terms of improved tumor coverage and lower doses to normal tissues for a variety of cancers originating in the NPC region. IMRT allows for fine modulation of radiation intensity within each radiation beam, which can achieve high dose in tumor without overdosing the normal organs [16,17]. It has been proven that IMRT techniques is superior to conventional technique with respect to technical advantages, local or regional control, critical organ sparing and treatment outcomes [26]. IMRT has been proven excellent in the NPC treatment, patients with at least 66.5 Gy to their target volumes had significantly less locoregional failure. The last randomized study showed that IMRT with different chemotherapy sequence produced similar outcomes in terms of OS, DFS, RFS and MFS rates [19]. Similarly, thus excellent results and less toxicities in our patients could be largely due to the IMRT applied. However, an unimagined univariate analysis showed that IMRT eliminated many independent prognostic factors compared with conventional radiotherapy, only age $>50$ years and anemia before radiotherapy were significantly associated with poor OS; Male, stage $\mathrm{T}$ or $\mathrm{N}$ and lymph node biopsy was not associated with RFS, DFS, MFS and OS. Multivariate analysis of prognostic factors in survival rates showed the same results, which implied IMRT did balance the effects of different chemotherapy pattern. The results maybe benefit from high dose distributing for tumor, and significant improvement profited from the IMRT. Especially, chemotherapy failed the independent prognostic factor, which presented more different from many randomized trials $[1,13,14,27,28]$. The present study implied concurrent and adjuvant chemotherapy provided no significant additive effect on local/regional control, MFS, DFS, and OS rates in advanced NPC patients, regardless of their $\mathrm{T}$-classification or nodal status, definitively treated with IMRT. A logical interpretability did bring IMRT into prominence; Secondly likelihood attributed to small sample size or nonrandom incident in present study; Other perhaps tumor characteristic in Northwest China represent the favorable prognosis compared with the disease in Southeast China [26,29]. EBV and histological types in Northwest are significant different from those in Southeast China. Patients present high EBV infection $>90 \%$ and major undifferentiated tumor in Southeast China, and EBV is a well-established risk factor for NPC [29] particularly in undifferentiated NPC [30]. Conversely, the present study showed that the EBV infection was only $15.9 \%$, the undifferentiated NPC was only $26.8 \%$ and all patients with EBV-positive were undifferentiated NPC, which implied EBV play an important role in the aetiology of this NPC histological type. Perhaps it caused the diversity prognosis of NPC between Southeast and Northwest China. High EBV prevalence in undifferentiated NPC prompts EBV should be a risk and poor prognosis factor for NPC [31,32]. Even so, two cases local/regional failures in the study were still marginal of field radiation, and failed to rescue by chemotherapy, which prompted the marginal of field should be considered carefully to broaden befittingly in high-risk patients.

The present data investigated, for the first time in Northwest China, the role of EBV in the aetiology of 
NPC has been eliminated. The findings prompted NPC in the low-incidence areas rarely represented undifferentiated carcinoma, which maybe include other nosogenesis, are different from Southeast China.

In summary, the present study showed NPC in Northwest China possesses remarkable different from NPC in Northwest, primary distinction represent in aetiology, pathology and prognosis. IMRT in Northwest China has achieved excellent results as well as an acceptable acute toxicity profile.

\section{Authors' contributions}

$\mathrm{SL}, \mathrm{XF}, \mathrm{FX}, J \mathrm{~L}, \mathrm{XL}, \mathrm{BZ}$ and $\mathrm{MX}$ participated in the treatment panning, contributed to the data collection. MS participated in its design and coordination and helped to draft the manuscript. JW, RL and YH conceived of the study, participated in the treatment panning, performed the statistical analysis, and drafted the manuscript. All authors read and approved the final manuscript.

\section{Competing interests}

The authors declare that they have no competing interests.

Received: 29 August 2011 Accepted: 10 January 2012

Published: 10 January 2012

\section{References}

1. Wei WI, Sham JST: Nasopharyngeal carcinoma. Lancet 2005, 365:2041-2054

2. Rottey S, Madani I, Deron P, Van Belle S: Modern treatment for nasopharyngeal carcinoma: current status and prospects. Curr Opin Oncol 2011, 23:254-258.

3. Zhang L, Zhao C, Ghimire B, Hong MH, Liu Q, Zhang Y, Guo Y, Huang YJ, Guan ZZ: The role of concurrent chemoradiotherapy in the treatment of locoregionally advanced nasopharyngeal carcinoma among endemic population: a meta-analysis of the phase iii randomized trials. BMC Cancer 2010, 10:558.

4. Teo P, Yu P, Lee WY, Leung SF, Kwan WH, Yu KH, Choi P, Johnson PJ: Significant prognosticators after primary radiotherapy in 903 nondisseminated nasopharyngeal carcinoma evaluated by computer tomography. Int J Radiat Oncol Biol Phys 1996, 36(2):291-304.

5. Kwong DL, Sham JS, Au GK, Chua DT, Kwong PW, Cheng AC, Wu PM, Law MW, Kwok CC, Yau CC, Wan KY, Chan RT, Choy DD: Concurrent and adjuvant chemotherapy for nasopharyngeal carcinoma: a factorial study. $J$ Clin Oncol 2004, 22(13):2643-2653.

6. Rossi A, Molinari R, Boracchi P, Del Vecchio M, Marubini E, Nava M, Morandi L, Zucali R, Pilotti S, Grandi C: Adjuvant chemotherapy with vincristine, cyclophosphamide, and doxorubicin after radiotherapy in local-regional nasopharyngeal cancer: results of a 4-year multicenter randomized study. J Clin Oncol 1988, 6(9):1401-1410.

7. Prasad U, Wahid MI, Jalaludin MA, Abdullah BJ, Paramsothy M, AbdulKareem S: Long-term survival of nasopharyngeal carcinoma patients treated with adjuvant chemotherapy subsequent to conventional radical radiotherapy. Int J Radiat Oncol Biol Phys 2002, 53(3):648-655.

8. Xu L, Pan J, Wu J, Pan C, Zhang Y, Lin S, Yang L, Chen C, Zhang C, Zheng W, Lin S, Ni X, Kong FM: Factors associated with overall survival in 1706 patients with nasopharyngeal carcinoma: Significance of intensive neoadjuvant chemotherapy and radiation break. Radiother Oncol 2010, 96(1):94-99.

9. Kalaghchi B, Kazemian A, Amouzegar Hashem F, Aghili M: Chemoradiation in nasopharyngeal carcinoma: a 6-year experience in tehran cancer institute. Acta Med Iran 2011, 49(1):49-53.

10. Lee AW, Lau WH, Tung SY, Chua DT, Chappell R, Xu L, Siu L, Sze WM, Leung TW, Sham JS, Ngan RK, Law SC, Yau TK, Au JS, O'Sullivan B, Pang ES, O SK, Au GK, Lau JT: Preliminary results of a randomized study on therapeutic gain by concurrent chemotherapy for regionally-advanced nasopharyngeal carcinoma: NPC-9901 Trial by the Hong Kong Nasopharyngeal Cancer Study Group. J Clin Oncol 2005, 23(28):6966-6975.
11. Dechaphunkul T, Pruegsanusak K, Sangthawan D, Sunpaweravong $P$ : Concurrent chemoradiotherapy with carboplatin followed by carboplatin and 5- fluorouracil in locally advanced nasopharyngeal carcinoma. Head Neck Oncol 2011, 3:30.

12. Lin JC, Jan JS, Hsu CY, Liang WM, Jiang RS, Wang WY: Phase III study of concurrent chemoradiotherapy versus radiotherapy alone for advanced nasopharyngeal carcinoma: positive effect on overall and progressionfree survival. J Clin Oncol 2003, 21(4):631-637.

13. Liu MT, Hsieh CY, Chang TH, Lin JP, Huang CC, Wang AY: Prognostic factors affecting the outcome of nasopharyngeal carcinoma. Jpn J Clin Oncol 2003, 33(10):501-508.

14. Lin S, Lu JJ, Han L, Chen Q, Pan J: Sequential chemotherapy and intensity-modulated radiation therapy in the management of locoregionally advanced nasopharyngeal carcinoma: Experience of 370 consecutive cases. BMC Cancer 2010, 10:39.

15. Cheng JC, Chao KS, Low D: Comparison of intensity modulated radiation therapy (IMRT) treatment techniques for nasopharyngeal carcinoma. Int J Cancer 2001, 96:126-131.

16. Shueng PW, Shen BJ, Wu LJ, Liao LJ, Hsiao CH, Lin YC, Cheng PW, Lo WC, Jen YM, Hsieh $\mathrm{CH}$ : Concurrent image-guided intensity modulated radiotherapy and chemotherapy following neoadjuvant chemotherapy for locally advanced nasopharyngeal carcinoma. Radiat Oncol 2011, 6:95.

17. Xiao WW, Huang SM, Han F, Wu SX, Lu LX, Lin CG, Deng XW, Lu TX, Cui NJ, Zhao C: Local control, survival, and late toxicities of locally advanced nasopharyngeal carcinoma treated by simultaneous modulated accelerated radiotherapy combined with cisplatin concurrent chemotherapy: Long-term results of a phase 2 study. Cancer 2011, 117(9):1874-1883.

18. Kwong DL, Sham JS, Leung LH, Cheng AC, Ng WM, Kwong PW, Lui WM, Yau CC, Wu PM, Wei W, Au G: Preliminary results of radiation dose escalation for locally advanced nasopharyngeal carcinoma. Int J Radiat Oncol Biol Phys 2006, 64(2):374-381.

19. Lee N, Harris J, Garden AS, Straube W, Glisson B, Xia P, Bosch W, Morrison WH, Quivey J, Thorstad W, Jones C, Ang KK: Intensity-modulated radiation therapy with or without chemotherapy for nasopharyngeal carcinoma: Radiation Therapy Oncology Group Phase II Trial 0225. J Clin Oncol 2009, 27(22):3684-3690.

20. Shanmugarantnam K, Sobin LH: Histological typing of tumors of the upper respiratory tract and ear. 2 edition. New York: Springer-Verlag; 1991.

21. Sobin LH, Wittekind Ch: UICC TNM classification of malignant tumors. 6 edition. Wiley, New York; 2002.

22. Fleming ID, Cooper JS, Henson DE, Hutter RVP: American joint committee on cancer: AJCC cancer staging manual. 5 edition. Philadelphia: LippincottRaven; 1997

23. Chen SW, Yang SN, Liang JA, Shiau AC, Lin FJ: Comparative dosimetric study of two strategies of intensity-modulated radiotherapy in nasopharyngeal cancer. Med Dosim 2005, 30(4):219-227.

24. Cox JD, Stetz J, Pajak TF: Toxicity criteria of the Radiation Therapy Oncology Group (RTOG) and the European Organization for Research and Treatment of Cancer (EORTC). Int J Radiat Oncol Biol Phys 1995, 31(5):1341-1346.

25. Huncharek $M$, Kupelnick $B$ : Combined chemoradiation versus radiation therapy alone in locally advanced nasopharyngeal carcinoma: results of a meta-analysis of 1,528 patients from six randomized trials. Am J Clin Oncol 2002, 25(3):219-223.

26. Lu H, Yao M: The current status of intensity-modulated radiation therapy in the treatment of nasopharyngeal carcinoma. Cancer Treat Rev 2008, 34(1):27-36.

27. Sarisahin M, Cila A, Ozyar E, Ylldlz F, Turen S: Prognostic significance of tumor volume in nasopharyngeal carcinoma. Auris Nasus Larynx 2011, 38(2):250-254.

28. Zhou JY, Chong VF, Khoo JB, Chan KL, Huang J: The relationship between nasopharyngeal carcinoma tumor volume and TNM T-classification: a quantitative analysis. Eur Arch Otorhinolaryngol 2007, 264(2):169-174.

29. Liu XQ, Luo W, Liu MZ, Ye L, Sun Y, Xia YF: Treatment results and prognostic analysis of 1093 primary nasopharyngeal carcinoma: the experience of a single institution of Guangzhou in the beginning of the 21st century. Chinese-German J Clin Oncol 2008, 7:187-195.

30. Hui EP, Ma BB, Leung SF, King AD, Mo F, Kam MK, Yu BK, Chiu SK, Kwan WH, Ho R, Chan I, Ahuja AT, Zee BC, Chan AT: Randomized phase II trial of concurrent cisplatin-radiotherapy with or without neoadjuvant 
docetaxel and cisplatin in advanced nasopharyngeal carcinoma. J Clin Oncol 2009, 27(2):242-249.

31. Chen J, Hu CF, Hou JH, Shao Q, Yan LX, Zhu XF, Zeng YX, Shao JY: EpsteinBarr virus encoded latent membrane protein 1 regulates mTOR signaling pathway genes which predict poor prognosis of nasopharyngeal carcinoma. J Transl Med 2010, 8:30.

32. Yu KJ, Hsu WL, Pfeiffer RM, Chiang CJ, Wang CP, Lou PJ, Cheng YJ, Gravitt P, Diehl SR, Goldstein AM, Chen CJ, Hildesheim A: Prognostic Utility of Anti-EBV Antibody Testing for Defining NPC Risk among Individuals from High-Risk NPC Families. Clin Cancer Res 2011, 17(7):1906-1914.

doi:10.1186/1748-717X-7-2

Cite this article as: Wang et al:: Failure patterns and survival in patients with nasopharyngeal carcinoma treated with intensity modulated radiation in Northwest China: A pilot study. Radiation Oncology 2012 7:2.

Submit your next manuscript to BioMed Central and take full advantage of:

- Convenient online submission

- Thorough peer review

- No space constraints or color figure charges

- Immediate publication on acceptance

- Inclusion in PubMed, CAS, Scopus and Google Scholar

- Research which is freely available for redistribution

Submit your manuscript at www.biomedcentral.com/submit 